Mental Health, Religion E Culture

January 2008; 11(1): 23-38

\title{
Meaning, God, and prayer: Physical and metaphysical aspects of social support
}

\author{
KEVIN L. LADD ${ }^{1} \&$ DANIEL N. McINTOSH ${ }^{2}$ \\ ${ }^{1}$ Indiana University South Bend, South Bend, USA and \\ ${ }^{2}$ University of Denver, Denver, USA
}

\begin{abstract}
This paper highlights unique aspects of social support in a religious context, with an emphasis on the practice of prayer. We first discus presuppositions that drive work in the area including (1) adoption of a "medical model" of evaluation and (2) the corollary influence of existential chauvinism. We next outline how religious groups differ from others with respect to the provision of meaning, the position of a deity, and the practice of prayer. Examining the latter facet in detail, we explore possible ways in which prayer is related to physical behaviors (e.g., folding hands, bowing head, closing eyes) that may promote and intensify internal experiences of social support independent of the actual content of the prayer itself.
\end{abstract}

\section{Preliminary considerations}

Religion

Religion linguistically refers to a binding together or unification. The emphasis of the concept of religion is on how it links humans together, and beyond the purely physical domain, to the supraphysical/supernatural realm. Attempts to cultivate an exclusively personalized, fundamentally self-referent "spirituality" necessarily lack the depth and breadth of other-oriented context that is critical for the execution of religious rituals that define the concept (McCauley \& Lawson, 2002). As such, it is possible to contend that without some form of interaction with entities outside of the self, religion per se is vastly weakened and perhaps even fails to exist. One obvious way in which the concept of religion takes on a tangible shape is through its power to generate and sustain interpersonal

Correspondence: Kevin L. Ladd, Department of Psychology, 1700 Mishawaka Ave., South Bend, IN, 46634-7111. E-mail: kladd@iusb.edu

ISSN 1367-4676 print/ISSN 1469-9737 online (C) 2008 Taylor \& Francis

DOI: $10.1080 / 13674670701475053$ 


\section{Kevin L. Ladd E Daniel N. McIntosh}

relationships, many of which take on systematic forms. The resultant network of interchanges and its maintenance create the sense of being bound together with others in both physical and metaphysical aspects. This experience in turn provides the basis for actual and imagined social support, as Ellison and George (1994) demonstrated with respect to attendance at religious services.

Given the centrality of relationships in both the definition and practice of religion, it is natural to inquire as to the ramifications of this situation. The body of research built over several decades reveals generally positive associations between religious service attendance and some indices of mental and physical health (Hackney \& Sanders, 2003; Koenig, McCullough, \& Larson, 2001). For example, McCullough and Larsen (1999) found in their review that people reporting a religious affiliation have a lower risk of depression than those who claim no such allegiance. Religious service attendance also predicts positive adjustment; in an 8-year longitudinal study, it was positively associated with life satisfaction, even with functional health statistically controlled (Markides, Levin, \& Ray, 1987). Perhaps the least controversial observation is a lower morbidity rate among regular attenders (Sloan, 2006), though causal links remain obscured.

\section{The medical model}

Investigations concerning the role of social support in the context of religious societies are routinely based on two unspoken but highly influential tenets: the appropriateness of the "medical model" and a closely related existential chauvinism. Within the medical model, social support is important or interesting to the extent that it is linked with particular, health-focused ends (e.g., blood pressure regulation, successful postoperative healing, cancer remission, etc.) (Williams \& Heslop, 2005). From this view, death is necessarily an enemy to be routed with the help of one's religious companions. Physical illness is to be avoided and, when encountered, vanquished with haste.

This approach has a strong corollary valuation of happiness and contentment as opposed to angst. The conditions of distress, especially physical but also psychological, are portrayed as anathema to the lives people should be living. Some ways of thinking, however, contend that there may be much to learn in the midst of affliction (Cavadini, 2007; Porterfield, 2007), whether unplanned (Weil, 1951 ) or in the guise of various forms of bodily or mental tribulation constituting rites of passage into full religious identification (McCauley \& Lawson, 2002; Sullivan, 2007). It is worth noting that especially in the latter instance, the role of social support is critical because the rite plunges the individual into an intentional state of chaos. Successful emergence from the predictable turmoil then "proves" the effectiveness and quality of the support that was provided during the trial by one's co-religionists. If, per the medical model, all pain is avoided, potentially important lessons concerning one's relation to fellow believers are forfeited.

Although more discussion in this vein is best reserved for other forums (Ladd, 2007a, 2007b; Sloan, 2006), we believe the medical model should be carefully scrutinized prior to wholesale acceptance within the field of the psychology of 
religion. Most important for our consideration of social support in religious societies is the point that the primary goal of social support within collections of people sharing a religious belief structure may not be extended physical existence and happiness, but instead may be such ends as spiritual growth, eternal life, fulfilling a perceived divine purpose, and the like. Any study of the nature and function of social support in religious organizations will suffer if the diverse participants' individual and group values and goals are ignored (Emmons, 1999). To the extent that the views emphasizing the uniquely religious origin of the goals and methods of social support differ from those of investigators coming from a predominantly medical model, such research will likely open new avenues and understandings. For example, the importance of prayer as a way to give and receive social support would likely receive more attention if investigators first considered how social support is instantiated in a religious context, often with religious goals arising from particular theological stances, whether or not the theologies are made explicit.

\section{Existential chauvinism}

A second presupposition that colors many investigations is what we refer to as existential chauvinism. Beck and Miller (2001) demonstrated the related notion of metaphysical chauvinism, arguing that metaphysical beliefs with similar levels of empirical support are not always treated equally with respect to endorsement. In a similar vein, existential chauvinism avers that an unwarranted preference is frequently bestowed upon the present state of existence as compared with any other state of being that may (or may not) follow death. The paucity of comparison data from those who are no longer manifestly alive leaves the relative value of the known state of existence an open question. For instance, one might argue that the reason people do not come back from the dead is because the "dead" state is so far superior to the "live" state. Those who are now "dead" may, in fact, wish they had not exerted so much effort to sustain their "live" status. Yet, choosing to die, even in the context of close, caring social support, is rarely deemed acceptable because it challenges the prevailing medical notion that the continuation and extension of life as we know it is the better option. A concrete example of how religious beliefs can lead to a lower prioritization of one's own physical survival vs. other goals was provided by a seminary president indicating that he expected students to charge any attacker who may appear, "Christians-who believe that heaven is their real home and that they are prepared for eternity as result of a life changed by Christ-are even more obligated to act courageously and sacrificially" (Hodges, 2007, para. 10). There are, of course, theological arguments to explore in this area as well, but those discussions lie beyond the scope of the present work.

One way that existential chauvinism is manifested within the sciences is that non-empirical forces are rarely considered in discussions of social support. Specifically, despite the insistence concerning the reality of a deity by those within 
religious societies, researchers are reticent to address the possibility of direct supraphysical/supernatural influences on the groups. The dilemma, of course, is that such activity is by definition beyond the ken of contemporary empirical science. Yet, if the religion context is taken seriously, existential chauvinism must be acknowledged. At a minimum, a tempering of the exclusivity of empirical conclusions by investigators is warranted (Sloan, 2006).

\section{Notions of social support}

Do not misconstrue the above points to suggest that we believe investigators should focus exclusively on death, pain, and inexplicable supernatural forces. Rather, our intent is to outline some of the presuppositions inherent in the bulk of the religion and social support literature. The standard approach to investigating social support in religion is either to compare the degree of social support (or health outcomes) of those who report "higher" levels of personal religiosity to those who report "lower" levels of such beliefs, or to examine the association of attendance with some presumed desirable outcome. The non-experimental nature of this methodology is obviously fraught with difficulties for making any conceptual leap from statistical significance to causality, yet the leap is commonly encountered. The conclusion that religiously derived social support is beneficial to some outcome (e.g., coping with some variety of trauma, better physical health) is a typical landing spot, though such conclusions are frequently not appropriate (Sloan, 2006).

The validity of such pronouncements tends to generate much discussion. If the social support associated with religious groups is truly more efficacious than other forms of support, then should religiously affiliated individuals pay less in health insurance premiums or be taxed less heavily since they put less strain on the health-care system? To maximize the speed and quality of healing, should physicians prescribe worship attendance in addition to pharmacological protocols? Should religious organizations base their proselytizing on the idea that mere membership in a religious group ameliorates life's vicissitudes?

As noted above, when the evidence is weighed, religious participation is associated with some positive life outcomes - both mental and physical health (Hackney \& Sanders, 2003; Koenig et al., 2001; Markides et al., 1987). It is in interpreting the meaning of this non-causal association that researchers and commentators alike often lapse into habitual ways of viewing people and institutions. Some with a proreligion, promedical standpoint see this as proof of the benefits of religion, and (despite the causal ambiguities in the research) call for the inclusion of religious practices in treatment for mental and physical conditions. Others take a less medical and more theological view, and use these data as evidence of divine blessing on religious belief or action; they are equally quick to discount as irrelevant any faith-contradictory research. Yet others with a less favorable view towards religion point out that this evidence is a mundane example of the influence of social support in general; any positive outcome associated with religion is mere social support. 
The latter group is correct to the degree that a binding together or a unification of people is by no means unique to religious organizations. In fact, highly successful, coping-enhancing, social support networks exist in a plethora of nonor even anti-religious contexts. Participation in the rites and rituals of any group takes remarkably similar forms. Formal and informal meetings, the sharing of

food, marking the passage of time with repetitious or discrete rituals, the use of music, distinctions between leaders and members, and giving of money and time all provide moments for interpersonal connectivity. Likewise, all these situations exist well beyond the bounds of religious organizations.

Those who reduce religion to nothing more than social support, or who see social support in religious societies as identical to support outside such collections, are missing the distinctive gestalt of religious social support. We argue that researchers who do not consider what may be unique about religion are missing an opportunity to understand more fully the variety of social support that people experience. (In parallel, we also understand that studies of the role of religion in people's lives that focus only on the internal, psychological processes of religion are failing to consider the functional differences between belief systems that are either idiosyncratic or nomothetic, and the extensive influence of the social components of religion).

\section{Uniquely religious social support}

We think that religious social support is distinguishable from other available networks for at least three reasons. First, and most thoroughly studied to date, within a milieu of believers one encounters an explicit, more or less coherent framework for understanding life. Few employment positions, fraternal, or sororital groups provide appealing answers to questions of meaning, but that is precisely the quandary with which religion deigns to grapple (Emmons, 1999). The difference is not that issues of meaning and purpose are irrelevant in nonreligious groups. Upon close inspection, one's employer or sports team may well try to tell one what the meaning of life is: "Your purpose is to help this group advance. Live for the organization. Sacrifice all else for the unit. Bad things happen to those who do not follow our set of rules". These non-religious groups establish norms and mores that exert great pressure on individuals, whether the conditions are explicit or tacit, but the messages do not plumb the same depths that religion explores. Religion also differs in that it typically willingly and explicitly divulges this agenda, and thus the degree of centrality such concerns have within the social functioning of the institution. Moreover, religion's proffered meanings may strike some observers as more palatable than the other options, and so people gravitate toward it. In either case, social support in religious organizations is openly saturated with considerations of ultimate meaning and values (and as other organizations move toward explicit concern with meaning, values, and purpose, the more they would resemble a religious society).

A second difference between social support in religious societies and nonreligious organizations is the added presence of social support from a deity. 
Science does not need to commit as to the objective existence of or underlying nature of the supernatural to accept that individuals can perceive the presence and support (or withdrawal of presence or absence of support) of a deity. In essence, this stance provides an exceptionally strong notion of secondary control. If a person's attempts to alter an objective situation fall short, the person can sustain the belief that all is still well, since the deity remains firmly in control vicariously vindicating the petitioner (Pargament, 2002; Rothbaum, Weisz, \& Snyder, 1982).

Finally, we note that a form of social support uniquely available in religion is prayer. Although one can witness prayers being offered in contexts that are not religiously oriented (e.g., at the opening of meetings such as the U.S. Congress, before and during statistics exams), it is apparent that the role of the prayer is far from central to those events. Within religious experience, however, prayer becomes the defining aspect of the moment (Heiler, 1932). Instead of fulfilling the role of a magical incantation that will help one team defeat the other, prayer in a religious setting is advocated as a means of metaphysically detailing the nature of the relationship between the divine, other people, and the true self (Ladd, Ladd, Baesler, \& Modée, 2007; Ladd \& Spilka, 2002, 2006).

Each of these three differences between non-religious and religious social support (provision of meaning, perceived presence of a deity, and the practice of prayer) is discussed further below. These should not be seen as independent factors-indeed, prayer links together issues of meaning and divine support, and part of the importance of prayer derives from the former two factors.

\section{An explicit framework for meaning}

Every religious system includes a set of explicit and implicit propositions held to be true (Spiro, 1987). Individuals who participate in a religious institution will at the very least be exposed informally to such propositions. Moreover, because part of the raison d'être of a religious institution is the promulgation and support of such beliefs, participation in a religious institution will repeatedly expose one to others who explicitly believe these propositions in a context in which discussion of such issues is not only allowed but encouraged.

The presence of this explicit framework contributes to social support in at least two related ways. First, the religious social network provides a ready resource that can be accessed readily when issues of meaning become salient; such a network may facilitate integration of stressful or traumatic events into one's beliefs about the world and oneself that leads to more positive postcrisis outcomes (McIntosh, 1995; McIntosh, Silver, \& Wortman, 1993). Although other social networks are also likely to provide instrumental and social support in times of crisis, it is the religious social network that is most prepared and motivated to provide support for meaning-making or cognitive processing of an event (McIntosh, Poulin, Silver, Holman, \& Gil-Rivas, 2003).

Second, unlike other social networks such as those experienced in employment, sporting teams, or neighborhoods, not only is the belief system explicit, but the 
relative congruence of one's worldview with the co-participants is explicit in a religious society. Indeed, this shared worldview is part of the reason for joint participation in the society. This explicit congruence may enhance social support, as one may feel more support from those with whom one shares a worldview (Hackney \& Sanders, 2003). Moreover, this explicit congruence may serve to support beliefs that are shaken by life events. Pargament (2002) posits that people who benefit most from their religion are likely to be a part of a larger social context that supports their faith. Others in the religious community may support one's beliefs and provide consonant cognitions (Festinger, 1957) that bolster the influence of the beliefs.

\section{Divine support}

As noted above, recognition and experience of the supernatural is part of most religious societies. The presence of this supernatural deity makes available a uniquely powerful source of support for the individual. One benefit of this is that the individual can experience vicarious control over difficult situations (Rothbaum et al., 1982). Indeed, people who believe they have a collaborative relationship with God experience better physical health (McIntosh \& Spilka, 1990). The experience of a loving God acting on one's behalf may also provide emotional support via attachment processes (Granqvist \& Hagekull, 1999, 2000, 2001; Kirkpatrick, 2005). Being a part of a religious society can enhance and make tangible this experience; religious individuals may interpret social support from fellow members of the religious community as the direct or indirect support of a deity (Krause, Ellison, \& Wulff, 1998).

\section{Prayer}

The understanding of any relation between religiosity and social support is linked inextricably to an explanation of the unifying characteristics of prayer. To the extent that indices of worship attendance frequency, intensity of religious beliefs, number of religious acquaintances, ability to recite revered texts, or other such measures demonstrate utility in predicting some outcome among religious adherents that is not observed among less, non-, or anti-religious individuals, we argue that those measures are likely functioning at least in part as distal records of prayer-related phenomena. The remainder of this paper is devoted to an exploration of the ways in which the uniquely religious practice of prayer functions with respect to social support.

\section{Defining prayer}

To ground the discussion, we define prayer as the typically intentional expression of one's self in an attempt to establish or enhance connectivity with the divine, with others in a religious or spiritual framework, and with the self. Note that although this definition can include some meditation practices, from our perspective, meditation is not necessarily identical to prayer. For example, meditation is focused on achieving enlightenment, self-awareness, or calm, 
frequently via breath control, repetition of a mantra, or detachment of thought or training attentional processes (Bouin, 2000; Canter, 2007; Valentine \& Sweet, 1999), while prayer tends toward communicative dialogue (Baesler, 2003; Ladd \& Spilka, 2002, 2006).

By "typically intentional", we mean that not all prayers arise under the influence of prior planning. Although many familiar examples of prayers include carefully crafted theological expositions, less widely accessible, intensely personal prayers have the potential for spontaneous creation (Heiler, 1932). Whether in the midst of trauma, excitation, or without obvious contextual provocation, people can be found engaging in unplanned prayer.

"Expression" incorporates both vocal and non-vocal acts. As demonstrated by the practice of glossolalia, vocal prayers need not be verbal in the sense of "recognizably linguistic". Some instances of spontaneous vocal prayer take the even less structured form of simple sound production (e.g., sighs, moans, cries). In contrast, non-vocal prayer employs no discernible sound. It shares with the vocal variety the characteristic that it may or may not take an explicitly linguistic form (e.g., silent textual reading vs. physical gesture of supplication); it may or may not be possible for the practitioner to verbalize a non-vocal prayer. Beyond the cognitive aspect of non-vocal prayer, we also recognize the possibility of prayer without complex cognition. Physical behaviors (e.g., touch, bowing, dance, prostration) are arguably the non-vocal equivalent to unstructured utterances. When language is unable to adequately serve the communicative function, these other modes of expression are sufficient, though not necessary, to enable continued prayer that is not fully within the practitioner's awareness.

We indicate in our definition that one's self is exposed during the course of prayer. On one hand, this means that a person's complete range of known motivations, emotions, and goals fall within the purview of prayer topics as they recollect the past, inhabit the present, and envision the future. Equally possible is that the person may be unaware of their motivations, emotions, and goals, and will utilize prayer as a mechanism for discovery. In other words, at some points the presentation of the self is declarative, and during other instances it is explorative.

The idea that prayer is "an attempt" highlights the fact that practitioners sometimes report that their prayers seem ineffective. The practice of prayer continues as before, but is devoid of any sense of spiritual energy. This portion of our definition does not address efforts to objectively evaluate success or failure of prayers, but only notes that the subjective experience can vacillate.

By including "to establish or enhance connectivity" as part of the definition of prayer, our intent is to highlight the idea that prayer functions as a means of entry into and development within the religious social circle. Although, for neophytes, praying may result primarily in tangible support (e.g., verbal encouragement and praise from group members), veterans of the practice instead report personal enrichment via prayer's ability to augment such physical connections with a metaphysical experience. 
Along with generations of other thinkers, we identify the divine, others, and the self as three targets of prayer's connectivity (cf. Spilka, 1977). Although it is possible to consider these as temporally bound targets, especially the latter two, we prefer a more broad interpretation that includes past, present, and future aspects. Most conceptions of the divine realm encompass this range at their definitional level, suggesting that the divine has always, is currently, and will continue indefinitely to exist. The perception of connectivity with the divine provides the individual with an exceptionally powerful social partner. Association with the divine, then, promotes a sense of vicarious control (Rothbaum et al., 1982) over such domains as the current or future distribution of justice, creative or destructive power, knowledge, and even longevity.

In the context of religious organizations, one encounters a similarly expansive understanding of one's relation to others and the self. The "others" to whom we stand in relation may be identified not only as those who currently participate in the group, but also as those who have at any point in the past contributed or who at some point in the future may contribute to the group at large, including strangers or enemies. By purporting to bind humans together, prayer offers practitioners access to fulfillment of pragmatic needs such as companionship from one's peers and non-threatening touch. Prayer is unique in that even when practiced in isolation, practitioners commonly claim experiences related to the sense of the presence of others and use language related to physical contact (e.g., "feeling the touch of the hand of God").

The religious "self" is also considered multidimensional with regard to time and space, with special emphasis on present and future (i.e., postlife) qualities. Reflection on personal attitudes, behaviors, and decisions is encouraged in the context of prayer that strives to exclude external stimuli in favor of internally focused concentration.

Most empirical investigations that include prayer as a component of interest do not delve into the complexities expressed above. Instead, the most common index of this behavior is the simple "frequency of prayer" item. While this single item is certainly a cost-effective way to gather important casual information, it is an obviously blunt empirical tool. Its application is akin to a physician gathering data on "frequency of meal consumption" in order to diagnose and treat the intricacies of diabetes.

\section{Prayer's invocation of social support}

As is evident, our conception of social support is broader than is typical. We highlight the fact that people engaging in the practice of prayer believe that it expands their social networks from tangible person-to-person connections to include any perceived interactions, even when such perceptions have as their focus intangible relationships (e.g., dead ancestors, deities). In support of this notion, we now turn our attention to mechanisms whereby prayer may achieve this widely distributed social support. Because a sizeable portion of the extant literature explores links among religion, social support, and health 
(Koenig \& Cohen, 2002; Plante \& Sherman, 2001), we speculate here on ways that prayer may trigger physiological phenomena that are relevant to the acquisition of social support.

\section{Prayer postures}

One of the most obvious ways to identify a person at prayer is by noting the stereotypic bodily postures that are common to the practice (though by no means required). Although different faith traditions and spiritual contexts are associated with different postures, quite common features include a downward bowing of the head toward clasped hands, accompanied by closed eyes and, frequently, a kneeling position. In physiological terms, the bowing of the head results in an increased blood flow to the head. It also causes a shifting of the chin, mouth, and soft palate that preferences nasal breathing. This type of inhalation results in deeper intake of air, cooling the blood supply and elevating blood oxygen content. These effects work to make the individual better prepared for the processing of information, and may increase positive affect (McIntosh, Zajonc, Vig, \& Emerick, 1997), two characteristics that may prime the person for positive social interactions. More generally, research on embodied cognition suggests that body postures are an influential and basic component of social perception (Reed $\&$ McIntosh, in press); prayer postures may affect both the likelihood and type of social and emotional experience individuals have.

Although such a condition of receptivity is critical to effective, tangible interpersonal relationships, social interactions can often provide much contradictory information. In other words, simply being prepared for pleasant interpersonal exchanges does not guarantee that actual contacts with others will meet these expectations. We believe that prayer increases the breadth of perceived social contact and also increases the extent to which that contact conforms to expectations. A bodily posture, such as the stereotypic bowing of the head, that heightens readiness to evaluate information may preference the expectancy congruent prayer communications over more inconsistent communications experienced in face-to-face situations. While the effect size associated with such gains is likely to be quite small, it is also probable that it is very consistent over time. We hypothesize that most important is the cumulative effect of engaging in the practice of prayer, especially when that practice employs a wide range of the physical behaviors described here. In other words, bodily postures can enhance prayer-related experiences, especially among "expert" practitioners.

Closely related to the attentional aspects allied with bowing the head is the closing of the eyes during prayer. The obvious immediate influence is a blocking out of potentially distracting visual stimuli. Less apparent is the fact that this stimuli-restrictive behavior may facilitate memory retrieval by focusing attention (Russell \& D'Hollosy, 1992). Given our definition of prayer as a broad search for social interaction, the closing of the eyes provides a distraction-free "screen" upon which to project relevant past events. Whether those exchanges were positive or negative, recent or long past, this "prayer screening" offers a very 
private context in which to recall and interpret. What makes prayer distinct from a simple memory exercise is context. In particular, prayer typically is engaged as part of some faith tradition that provides direction for the activity. This direction commonly includes an explicit movement from the distant past toward the more recent and into the future.

Another facet awaiting explicit empirical exploration centers on the folding of the hands that provides relatively unique self-generated tactile sensation; most people do not hold their own hands for extended periods of time in other contexts. The importance of physical touch in the development of social relations is well documented (Hertenstein, Verkamp, Kerestes, \& Holmes, 2006); touch appears to be the non-verbal channel most connected with communication of emotions of intimacy (App, McIntosh, \& Reed, 2007). Thus, this prayer gesture clearly mimics tangible interaction with others, and is experientially associated with communication of intimate relationship. As prayer becomes more fervent, in our view indicating a greater desire for connectivity, the folded hands are frequently drawn upward and inward to rest upon the chest. This maneuver, when coupled with the bowed head, often results in a pressing of the lips against the hands suggestive of a prolonged self-kiss. The overall effect of this combination of motions is to move the body into a strikingly fetal position, nearly complete with the sucking of the thumb. These events are all in line with our hypothesis that more intense prayer experiences link to a desire for greater connectivity, for as prayer intensifies, so does self-stimulation in fashions that represent increasingly more intimate forms of social touch. Of course, different prayer goals may be associated with different postures. Tilting the head back, expanding the posture, and raising the arms communicates success and a bid for social status (Tracy \& Robbins, 2004); prayers associated with such a posture may communicate different emotions and motives (see App et al., 2007) but are still related to social connectivity.

\section{Speculations concerning social support, prayer, and psychoneuroimmunology}

Also demanding consideration is the burgeoning literature linking religion and health (Koenig \& Cohen, 2002; Plante \& Sherman, 2001). In particular, we are intrigued by work that argues in the following vein: religiosity is related positively to increased social support (real and perceived), and elevated social support is tied to better immunological functioning. In other words, religiosity, at least indirectly, can influence health status. Relatively unexplored is the mechanism binding religion, social support, and health. Generalization of the results from the bulk of the religion-health studies is routinely limited by operationalizations of religion that fail to adequately cover the conceptual domain.

From our perspective, one of the most critical omissions revolves around the practice of prayer. When included, as noted above, the frequency of prayer is the most common item representing the issue at a very gross level of measurement. As our definition demonstrates, frequency of prayer alone discloses an exceptionally 


\section{Kevin L. Ladd E Daniel N. McIntosh}

narrow facet of this discipline that is at the heart of religiosity. To avoid this paucity of measurement, multidimensional indices of prayer, as described above in our definition of prayer, are a necessity. One recent empirically developed and validated example (Ladd, Ladd, Ashbaugh, et al., 2007; Ladd, Ladd, Harner, et al., 2007; Ladd \& Spilka, 2002, 2006) explores how the cognitive contents of prayers are associated with desires to develop inward, outward, and upward connectivity. Drawing from theological as well as psychological principles, inward-oriented prayers involve a search to better know one's self. Outward prayers serve to unite the self with the experiences of others, and upward prayers focus on the relationship between the practitioner and the divine.

How, then, might differing aspects of prayer serve to explain the observed association between religion and health? One speculation is that potential illness may activate physiological drives toward companionship. For instance, as immune cells respond to invasive agents, the cytokines released may trigger a reaction in the hypothalamic-pituitary-adrenal axis, a portion of which encourages engagement in care giving/receiving behaviors (Carter, 1998). Prayer may function as an exogenous trigger of a similar physiological chain of events. This could be because prayer represents an exceptionally accessible form of engaging in caretaking behaviors (e.g., intercessory prayer), even without the presence or knowledge of the care receivers. Likewise, people can perceive that others are praying for them, whether or not the others actually pray. Such hyper-available social interaction/ support may increase immunological responses to an extent that is greater than typical, physically tangible varieties. Hence, links between religion and health, in the sense of immunological functioning, may be the result of prayer's ability to meet the human's built-in need to provide and receive caretaking.

Another possibility is that prayer's role as a provider of contextual meaning and social interactions (tangible or otherwise) keeps a person's perceptions of internal or external stress well under control. The accompanying lowered levels of oxytocin are associated with positive emotional states (Heinrichs, Baumgartner, Kirschbaum, \& Ehlert, 2003), a condition likely to promote more effective and extensive social support experiences. The resulting diversified network of supportive individuals helps to lessen illness experiences, by either buffering against initial contraction or ameliorating severity.

In short, the above scenario hypothesizes that prayer can enable the establishment of mythic (in the formal sense of the word) communities of limitless size transcending both temporal and spatial boundaries. These intangible groups, perceived as encouraging, can then influence interpretations of objective events, with those interpretations having ramifications for physical well-being and objective support. Data are currently being collected in the first author's lab to test several of the above hypotheses.

\section{Conclusion}

The existence of an association between religious participation and received and perceived social support on the one hand, and positive health outcomes on the 
other hand, warrants continued investigation of social support in religious contexts and institutions. However, we argue here that progress in understanding the nature and importance of social support in religious contexts depends on a richer understanding of what processes of social support might be unique or at least more emphasized in religion. Explicit issues of meaning, the influence of the claimed experience of support from a deity, and prayer are three fundamental areas for investigation.

We also offer some caveats in our analysis. Some of these factors discussed are based on an assumption of the voluntary nature of religious participation. In cultural contexts in which the religious institution is the primary site of social activities regardless of internalization of belief, processes are likely to differ and probably be less unique. Attending religious services may be less likely to create a network of fellow believers if, for example, attendance is so normative as to be compulsory. In these cases, however, we believe that a more theoretically informed focus on the three factors discussed here (provision of meaning, perceived powerful deity, roles of prayer) will be helpful in understanding for whom and why involvement in a religious social network is important.

It is also important to note that the importance of the deity and prayer are unique to religion among social institutions, but can also occur outside of such societies. We propose, however, that some of the importance of these factors (e.g., the action of others in the religious community as proxy support from the supernatural, and the experience of others praying for one) is tightly tied to social processes within a religious institution. Finally, we note that not all social processes within a religious society are positive. Ostracism and contingent support are certainly possibilities. For example, individuals experiencing non-family stress reported greater levels of religious support than did those experiencing family stress, perhaps because of sanctions against expressing domestic difficulties in a religious setting (Strawbridge, Shema, Cohen, Roberts, \& Kaplan, 1998).

Social support is important, regardless of whether it occurs in a religious institution. A full understanding of social support, however, requires that we study how it manifests in unique ways across contexts. Moreover, a complete understanding of the role of religion in people's lives requires examining not only the private aspects of belief but also the social processes that occur when one participates in a religious institution.

\section{Acknowledgement}

This work was supported in part by grant \#12282 from the John Templeton Foundation to the first author.

\section{References}

App, B., McIntosh, D. N., \& Reed, C. L. (2007, January). A social-functional approach to emotion communication: How depends on why. Paper presented at the Society for Personality and Social Psychology annual meeting, Memphis, TN. 


\section{Kevin L. Ladd E Daniel N. McIntosh}

Baesler, E. J. (2003). Theoretical explorations and empirical investigations of communication and prayer. Lewiston, NY: Edwin Mellen Press.

Beck, R., \& Miller, J. P. (2001). Erosion of belief and disbelief: Effects of religiosity and negative affect on beliefs in the paranormal and supernatural. Fournal of Social Psychology, 141, 277-287.

Bouin, Y. P. (2000). Effects of meditation on respiration and the temporal lobes. Lund, Sweden: Lund University Press.

Canter, P. H. (2007). The therapeutic effects of meditation. British Medical fournal, 326, 1049-1050.

Carter, C. S. (1998). Neuroendocrine perspectives on social attachment and love. Psychoneuroendocrinology, 23(8), 779-818.

Cavadini, J. (2007). Suffering in Christianity. Invited presentation at the Faith and Health conference, University of Notre Dame, Notre Dame, IN.

Ellison, C. G., \& George, L. K. (1994). Religious involvement, social ties, and social support in the southeastern community. Fournal for the Scientific Study of Religion, 33, 46-61.

Emmons, R. A. (1999). The psychology of ultimate concerns. New York: Guilford.

Festinger, L. (1957). A theory of cognitive dissonance. Stanford, CA: Stanford University Press.

Granqvist, P., \& Hagekull, B. (1999). Religiousness and perceived childhood attachment: Profiling socialized correspondence and emotional compensation. Fournal for the Scientific Study of Religion, 38, 254-273.

Granqvist, P., \& Hagekull, B. (2000). Religiosity, adult attachment, and why "singles" are more religious. The International fournal for the Psychology of Religion, 10, 111-123.

Granqvist, P., \& Hagekull, B. (2001). Seeking security in the new age: On attachment and emotional compensation. Fournal for the Scientific Study of Religion, 40, 529-547.

Hackney, C. H., \& Sanders, G. S. (2003). Religiosity and mental health: A meta-analysis of recent studies. Fournal for the Scientific Study of Religion, 42, 43-55.

Heiler, F. (1932). Prayer: A study in the history and psychology of religion. New York: Oxford University Press.

Heinrichs, M., Baumgartner, T., Kirschbaum, C., \& Ehlert, U. (2003). Social support and oxytocin interact to suppress cortisol and subjective responses to psychosocial stress. Biological Psychiatry, 54, 1389-1398.

Hertenstein, M. J., Verkamp, J. M., Kerestes, A. M., \& Holmes, R. M. (2006). The communicative functions of touch in humans, nonhuman primates, and rats: A review and synthesis of the empirical research. Genetic, Social and General Psychology Monographs, 132(1), 5-94.

Hodges, S. (2007, April 24). Students told to charge in an attack [Electronic version]. The Dallas Morning News. Retrieved April 24, 2007, from http://www.dallasnews.com/sharedcontent/dws/ $\mathrm{dn} /$ latestnews/stories/DN-patterson 24met.ART.State.Edition1.43177bb.html.

Kirkpatrick, L. A. (2005). Attachment, evolution, and the psychology of religion. New York: Guilford.

Koenig, H. G., \& Cohen, H. J. (2002). The link between religion and health: Psychoneuroimmunology and the faith factor. New York: Oxford University Press.

Koenig, H. G., McCullough, M. E., \& Larson, D. B. (2001). Handbook of religion and health. New York: Oxford University Press.

Krause, N., Ellison, C. G., \& Wulff, K. M. (1998). Church-based emotional support, negative interaction, and psychological well-being: Findings from a national sample of Presbyterians. Fournal for the Scientific Study of Religion, 37, 725-741.

Ladd, K. L. (2007a). Faith and health: Religion and magic. Invited presentation at the Faith and Health conference, December, University of Notre Dame, Notre Dame, IN.

Ladd, K. L. (2007b). Inward, outward, upward prayer: Practices of "spiritual," "religious," and "both" individuals. Paper presented at the Division 36, American Psychological Association MidWinter conference on Religion and Spirituality, March, Columbia, MD.

Ladd, K. L., Ladd, M. L., Baesler, E. J., \& Modée, J. (2007). Inward, outward, upward prayer: The psychological role of artifacts in religion. Paper to be presented at the meeting of the Society for the Scientific Study of Religion, November, Tampa, FL. 
Ladd, K. L., Ladd, M. L., Ashbaugh, P., Trnka, D., Harner, J., St. Pierre, K., et al. (2007). Inward, outward, upward prayer and personal character. Research in the Social Scientific Study of Religion, special section on Positive Psychology, Religion, and Spirituality, 18, 209-231.

Ladd, K. L., Ladd, M. L., Harner, J., Swanson, T., Metz, T., Haubold, K., et al. (2007). Inward, outward, and upward prayer: Links to personality (Big Five). Archiv für Religionspsychologie, 49, $151-175$.

Ladd, K. L., \& Spilka, B. (2002). Inward, outward, upward: Cognitive aspects of prayer. fournal for the Scientific Study of Religion, 41, 475-484.

Ladd, K. L., \& Spilka, B. (2006). Inward, outward, upward prayer: Scale reliability and validation. Fournal for the Scientific Study of Religion, 45(2), 233-251.

Markides, K. S., Levin, J. S., \& Ray, L. A. (1987). Religion, aging, and life satisfaction: An eightyear, three-wave longitudinal study. Gerontologist, 27, 660-665.

McCauley, R. N., \& Lawson, E. T. (2002). Bringing ritual to mind: Psychological foundations of cultural forms. New York: Cambridge.

McIntosh, D. N. (1995). Religion as schema, with implications for the relation between religion and coping. The International fournal for the Psychology of Religion, 5, 1-16.

McIntosh, D. N., Poulin, M. J., Silver, R. C., Holman, E. A., \& Gil-Rivas, V. (2003, April). Religion, well-being, and distress in the year following 9/11: A nationwide longitudinal study. Paper presented at the meeting, Integrating Research on Spirituality and Health and Well-being into Service Delivery: A Research Conference, Bethesda, MD.

McIntosh, D. N., Silver, R. C., \& Wortman, C. B. (1993). Religion's role in adjustment to a negative life event: Coping with the loss of a child. Fournal of Personality and Social Psychology, $65,812-821$.

McIntosh, D. N., \& Spilka, B. (1990). Religion and physical health: The role of personal faith and control beliefs. Research in the Social Scientific Study of Religion, 2, 167-194.

McIntosh, D. N., Zajonc, R. B., Vig, P. S., \& Emerick, S. W. (1997). Facial movement, breathing, temperature, and affect: Implications of the vascular theory of emotional efference. Cognition and Emotion, 11, 171-195.

McCullough, M. E., \& Larson, D. B. (1999). Prayer. In W. R. Miller (Ed.), Integrating spirituality into treatment (pp. 85-110). Washington: American Psychological Association.

Pargament, K. I. (2002). The bitter and the sweet: An evaluation of the costs and benefits of religiousness. Psychological Inquiry, 13, 168-181.

Plante, T. G., \& Sherman, A. C. (Eds.). (2001). Faith and health: Psychological perspectives. New York: Guilford.

Porterfield, A. (2007). The role of healing in the history of Christianity. Invited presentation at the Faith and Health conference, University of Notre Dame, Notre Dame, IN.

Reed, C. L., \& McIntosh, D. N. (in press). The social dance: On-line body perception in the context of others. In R. L. Klatzky, M. Behrmann, \& B. MacWhinney (Eds.), Embodiment, ego-space, and action: 34th Carnegie Symposium on Cognition. Hillsdale, NJ: Erlbaum.

Rothbaum, F., Weisz, J. R., \& Snyder, S. (1982). Changing the world and changing the self: A two process model of perceived control. Fournal of Personality and Social Psychology, 42, 5-37.

Russell, E. W., \& D’Hollosy, M. E. (1992). Memory and attention. Fournal of Clinical Psychology, 48(4), 530-538.

Sloan, R. P. (2006). Blind faith: The unholy alliance of religion and medicine. New York: St. Martin's Press.

Spilka, B. (1977). The compleat person. Fournal of Psychology and Theology, 4, 15-24.

Spiro, M. E. (1987). Religion: Problems of definition and explanation. In B. Kilborne \& L.L. Langness (Eds), Culture and human nature: Theoretical papers of Melford E. Spiro (pp. 187-222). Chicago, IL: University of Chicago Press.

Strawbridge, W. J., Shema, S. J., Cohen, R. D., Roberts, R. E., \& Kaplan, G. A. (1998). Religiosity buffers effects of some stressors on depression, but exacerbates others. Fournal of Gerontology, $53 B, \mathrm{~S} 118-\mathrm{S} 126$. 


\section{Kevin L. Ladd E Daniel N. McIntosh}

Sullivan, L. (2007). The role of healing in world religions. Invited presentation at the Faith and Health conference, University of Notre Dame, Notre Dame, IN.

Tracy, J. L., \& Robbins, R. W. (2004). Show your pride: Evidence for a discrete emotion expression. Psychological Science, 15, 194-197.

Valentine, E. R., \& Sweet, P. L. G. (1999). Meditation and attention: A comparison of the effects of concentrative and mindfulness meditation on sustained attention. Mental Health, Religion and Culture, 2, 59-70.

Weil, S. (1951). Waiting for God. New York: Putnam.

Williams, V., \& Heslop, P. (2005). Mental health support needs of people with a learning difficulty. Disability and Society, 20(3), 231-245. 